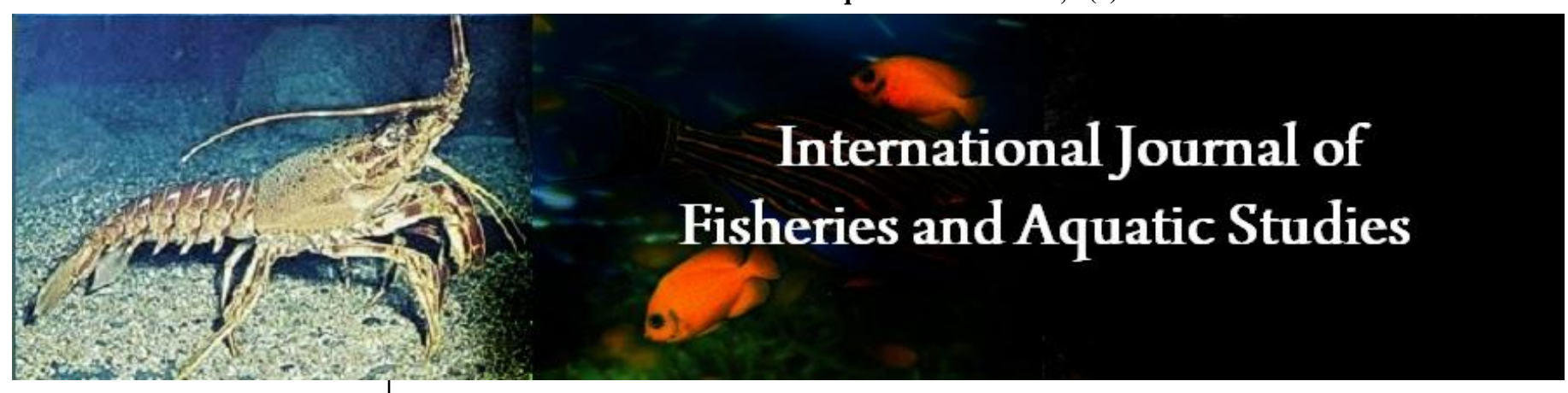

E-ISSN: 2347-5129

P-ISSN: 2394-0506

(ICV-Poland) Impact Value: 5.62

(GIF) Impact Factor: 0.549

IJFAS 2021; 9(2): 245-249

(C) 2021 IJFAS

www.fisheriesjournal.com

Received: 07-01-2021

Accepted: 09-02-2021

Aruna Mallavali

Dept of Zoology, J.M.J. College

for Women (A), Morris Pet,

Sarala Nagar, Tenali, Guntur,

Andhra Pradesh and India

\section{A case study on infection of trematodes pathogenicity in wild Channa striata collected from various freshwater ponds in Guntur district rural, semirural and urban areas}

\author{
Aruna Mallavali
}

DOI: $\underline{\text { https://doi.org/10.22271/fish.2021.v9.i2d.2458 }}$

\begin{abstract}
The Murrels (Channa striatus) is an indigenous, predatory freshwater fish. It is also known as lay man fish food with pharmacological benefits in treating wound and pain and in boosting energy of the sick. Amino acids include glycine, lysine and arginine and fatty acids are namely arachidonic acid, palmitic acid and docosahexaenoic acid are used for the preparation of several types of bioactive molecules commercially. Antinociceptive activity or toxic inhibitor, anti-depressant and neuroregenerative agent and it has wide-ranging medical uses. Henceforth the present study aimed to conduct the general survey by collecting various fresh water wild Channa striatus in Guntur district to investigate to identification of pathogenicity of trematodes and its affect on Channa striatus morphological, physiological and anatomical changes leads to the loss of nutritional, medicinal properties. Furthermore creating awareness to the target area where collected the samples about the pathogenicity impact on human health and their influences. Our results demonstrate that intestinal flukes are common in farmed fish in this area, suggesting that reservoir hosts such as dogs, cats, and pigs are more important in sustaining the life cycles of these fluke in fish farms than human hosts. This has implications for the effectiveness of control programs focused mainly on treatment of humans.
\end{abstract}

Keywords: human health, economic food, traditional nutritive food, amino acids, bioactive compounds, medicinal properties, hosts, fresh water ponds, pathogenicity, trematodes, awareness camp, pharmacological benefits, Channa striatus

\section{Introduction}

India is endowed with many freshwater resources, rich fish genetic biodiversity $(2,200$ fish species) and ranks $9^{\text {th }}$ in terms of freshwater mega diversity (Rubina Mondal and Anuradha Bhat, (2020) ${ }^{[8]}$. Nevertheless, a significant portion of the freshwater fish production in India is still based on the harvest from wild population (Vijay Anand P.E. (2019) ${ }^{\text {[9] }}$. In tropical regions, parasites are major concern to freshwater and marine fishes (Morales-Serna et al., 2019) ${ }^{[10]}$. They constitute a major limiting factor to the growth of farmed fish (Prangnell, David et al., 2016) ${ }^{[11]}$. They play a vital role in devaluation of nutrients alteration of biology and behaviour inducing blindness and in decreasing immunity reduction of growth and fecundity, increasing mortality and morbidity and they also causes mechanical injuries based on number and site of infection (Bichi et al., (2020) and Nmor et al., (2020).

Moreover, parasites may also control host population dynamics and manipulate community structure (Marcogliese David, (2004) ${ }^{[14]}$. Parasitology is an ever going discipline in research. The host parasite associations are unique in the sense that of the two organisms it is only the parasites that is benefited while the host suffers (Stothard, et al., 2018) ${ }^{[16]}$. The valuable information pertaining to the ecological aspects of freshwater fishes was contributed by several parasitologists of national and international status (Gozlan et al., 2010 and Kiruba-Sankar et al., 2018) ${ }^{[17,18]}$. At present, very few records of parasitic helminths in the study were documented (Garcia et al., 2018) ${ }^{[15]}$. The present research focused on to bring out the community characteristics of the metazoan parasite fauna identification in wild Channa species of freshwater fish collected from various ponds located in Guntur district of Andhra Pradesh.
Corresponding Author: Aruna Mallavali Dept of Zoology, J.M.J. College for Women (A), Morris Pet, Sarala Nagar, Tenali, Guntur, Andhra Pradesh and India 


\section{Methodology}

The present investigation dealing with parasitic diseases particularly trematode parasites take hosting of Channa striata collected from different ponds located in Guntur district, Andhra Pradesh been selected for a period of one year from July 2017- June 2018. Fish sampling was done by cast netting; usually in the morning hours between 6 to 9 am and a minimum of 50 fish were netted each time. Examined the collected Fish for any disease symptoms were investigated. Samples were transferred to the zoology laboratory, J.M.J. College for women (A) in live and also moribund condition to conduct autopsy for further studies. Each fish was weighed and its total length was measured. It was then dissected the open viscera and observed for the trematode parasites. Each intestine was opened with a mid-ventral incision along the ventral bold vessel and intestine mucosa was exposed so as to examine surfaces of each chambers. All the parasites were collected and kept in the petridish with saline solution separately. For identification the trematodes were fixed, stained and whole mount were prepared according to the conventional technique.

To know the monthly changes of trematodes infection rates, prevalence, one an intensity, density of infection have been calculated for the each month in the study period July, 2017 to June, 2018. Data on monthly prevalence of infection, seasonal distribution and severity and type of infection were recorded. A standard data sheet was prepared to take details like total number of fish collected, number of infected and uninfected fish.

\section{Results and Discussion}

The present work was under taken the incidence of and seasonal prevalence of trematode parasites of murrel Channa striata from various fresh water ponds located in the Guntur district Andhra Pradesh. Data of prevalence of trematode infection with different genus of trematodes was recorded in a period of one year. The assessment of the prevalence was based on the parasites obtained from internal organs of the fish.

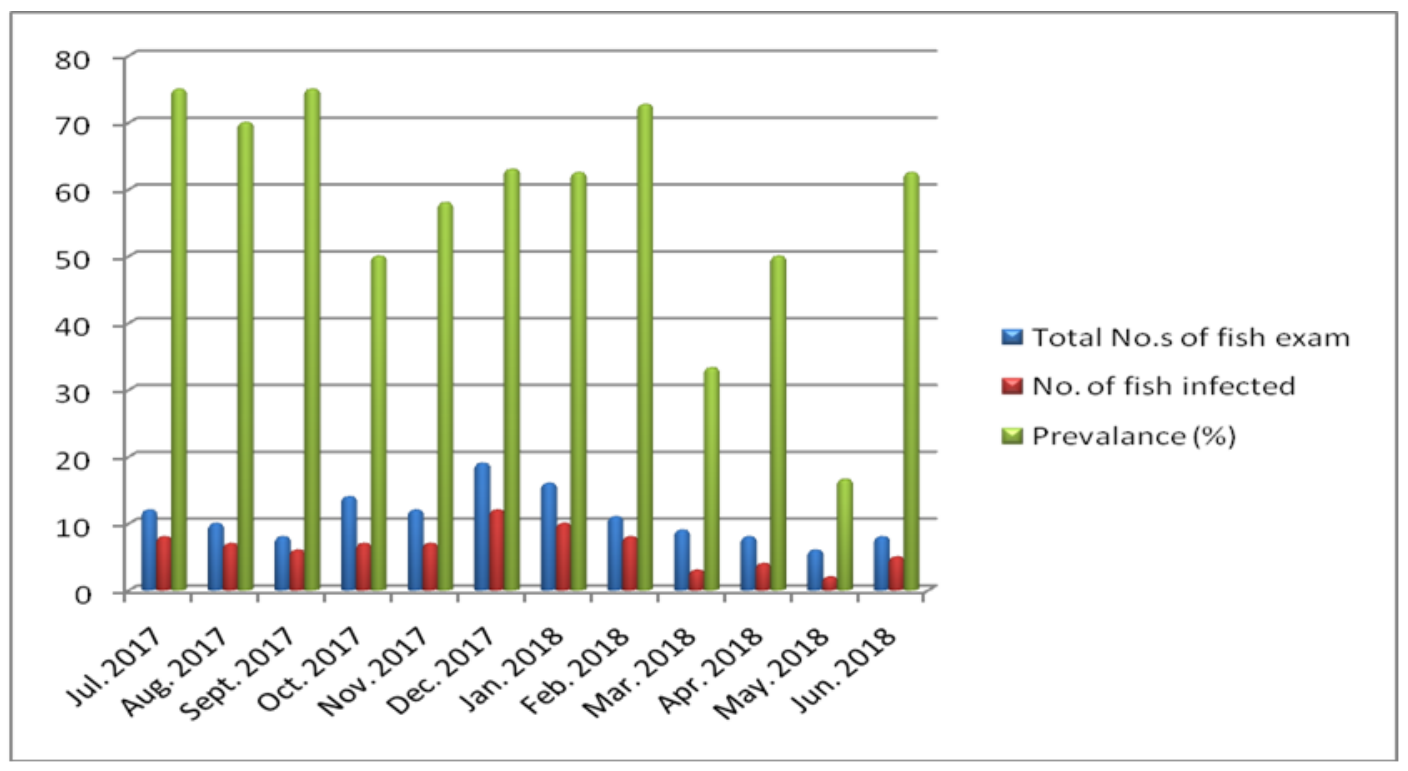

Fig 1: Monthly variations in overall prevalence of trematode in fection during 2017-118

Studies of prevalence: A total of 133 fishes were collected from various ponds of Guntur district. Out of 133, 79 fishes are infected. Months wise prevalence and mean, intensity was given (Table 1).

Table 1: Prevalance and mean intensity of trematodes parasite in Channa striata from of Guntur district during different months.

\begin{tabular}{|l|c|c|c|c|c|}
\hline Month & $\begin{array}{l}\text { Total No.s } \\
\text { of fish } \\
\text { exam }\end{array}$ & $\begin{array}{l}\text { No. of fish } \\
\text { infected }\end{array}$ & $\begin{array}{l}\text { Total No. of } \\
\text { parasites }\end{array}$ & $\begin{array}{l}\text { Prevalanc } \\
\text { e (\%) }\end{array}$ & $\begin{array}{l}\text { Mean } \\
\text { intensity }\end{array}$ \\
\hline July, 2017 & 12 & $\mathbf{8}$ & 14 & 75 & 1.75 \\
\hline August, 2017 & 10 & 7 & 16 & 70 & 2.28 \\
\hline September, 2017 & $\mathbf{8}$ & $\mathbf{6}$ & 18 & 75 & 3.0 \\
\hline October, 2017 & 14 & 7 & 20 & 50 & 2.85 \\
\hline November, 2017 & 12 & 7 & 18 & 58 & 3.6 \\
\hline December, 2017 & 19 & 12 & 21 & 63 & 2.6 \\
\hline January, 2018 & 16 & 10 & 29 & 62.5 & 2.9 \\
\hline February, 2018 & 11 & $\mathbf{8}$ & 13 & 72.7 & 2.1 \\
\hline March, 2018 & 9 & 3 & 8 & 33.3 & 2.6 \\
\hline April, 2018 & $\mathbf{8}$ & 4 & 12 & 50 & 3.0 \\
\hline May, 2018 & 6 & 2 & 4 & 16.6 & 2.0 \\
\hline June, 2018 & $\mathbf{8}$ & $\mathbf{5}$ & 12 & 62.5 & 2.4 \\
\hline Total: & 133 & 79 & 185 & 688.6 & 31.08 \\
\hline
\end{tabular}




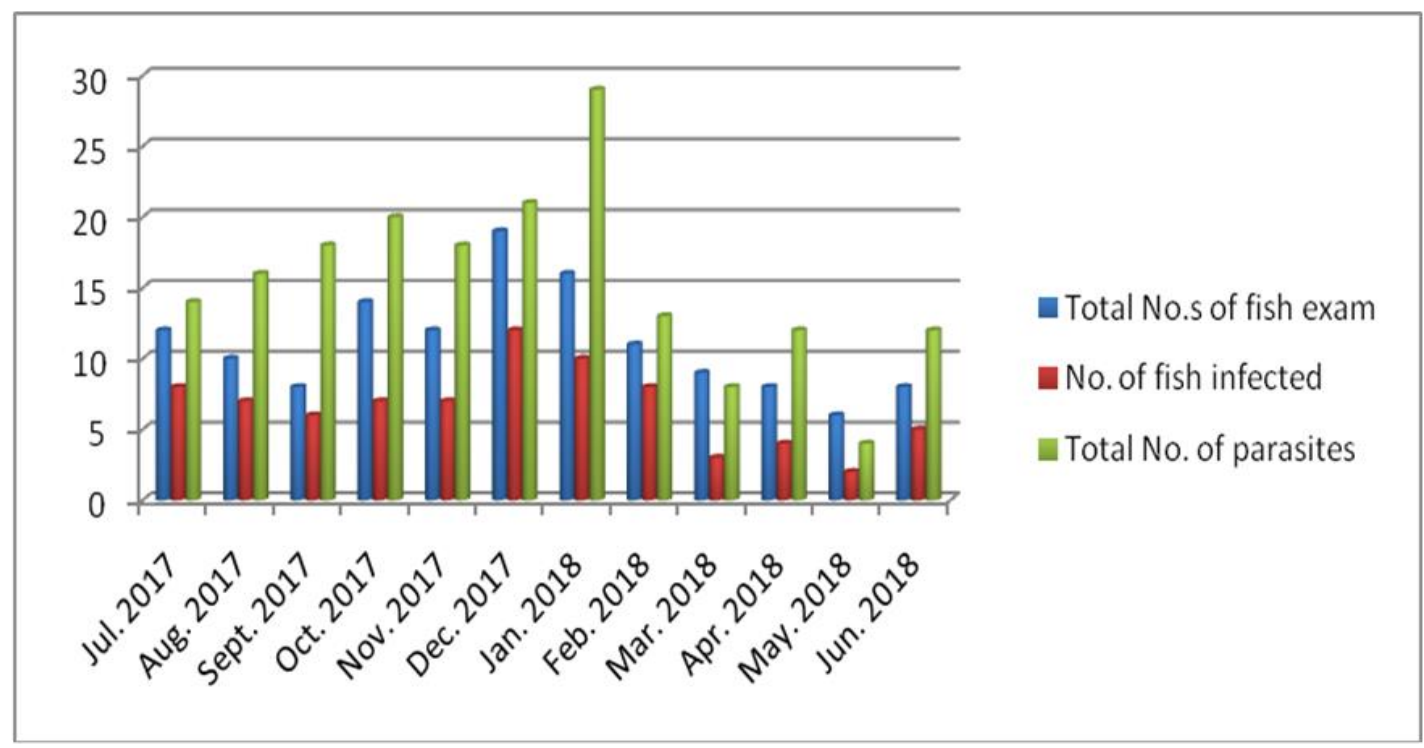

Fig 2: monthly variation total number of parasites infection during 2017-18

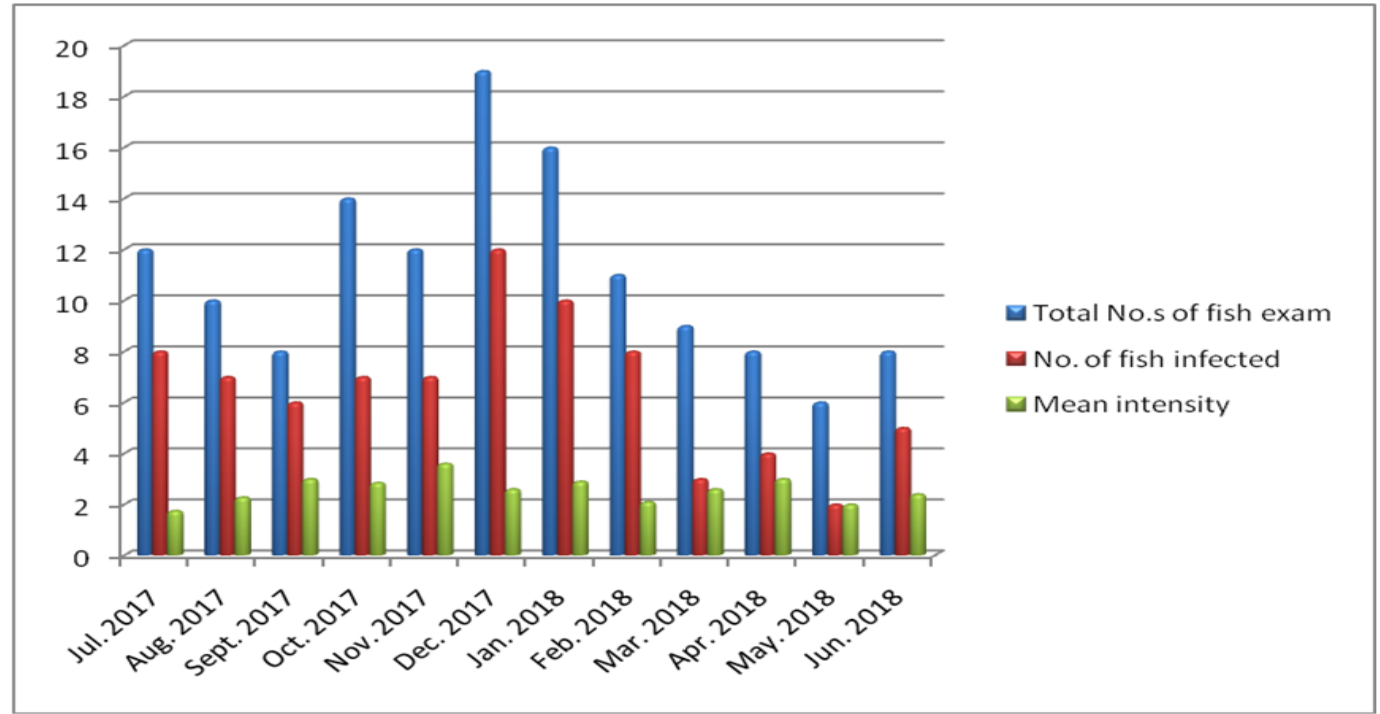

Fig 3: Monthly-variations in mean intensity of trematode infection during 2017-18

The trematode infection of Channa stiata from ponds/creeks and canals of Guntur district during different seasons was

given Table 2 .

Table 2: Percentage trematodes parasite infection of channa striata of Guntur district during different seasons

\begin{tabular}{|l|c|c|c|}
\hline Season & Total No. of fish exam & No. of fish infected & Percentage of Infection \\
\hline Rainy & 44 & 28 & 63.6 \\
\hline Winter & 58 & 37 & 63.7 \\
\hline Summer & 31 & 14 & 45.1 \\
\hline Total: & 133 & 79 & 172.4 \\
\hline
\end{tabular}




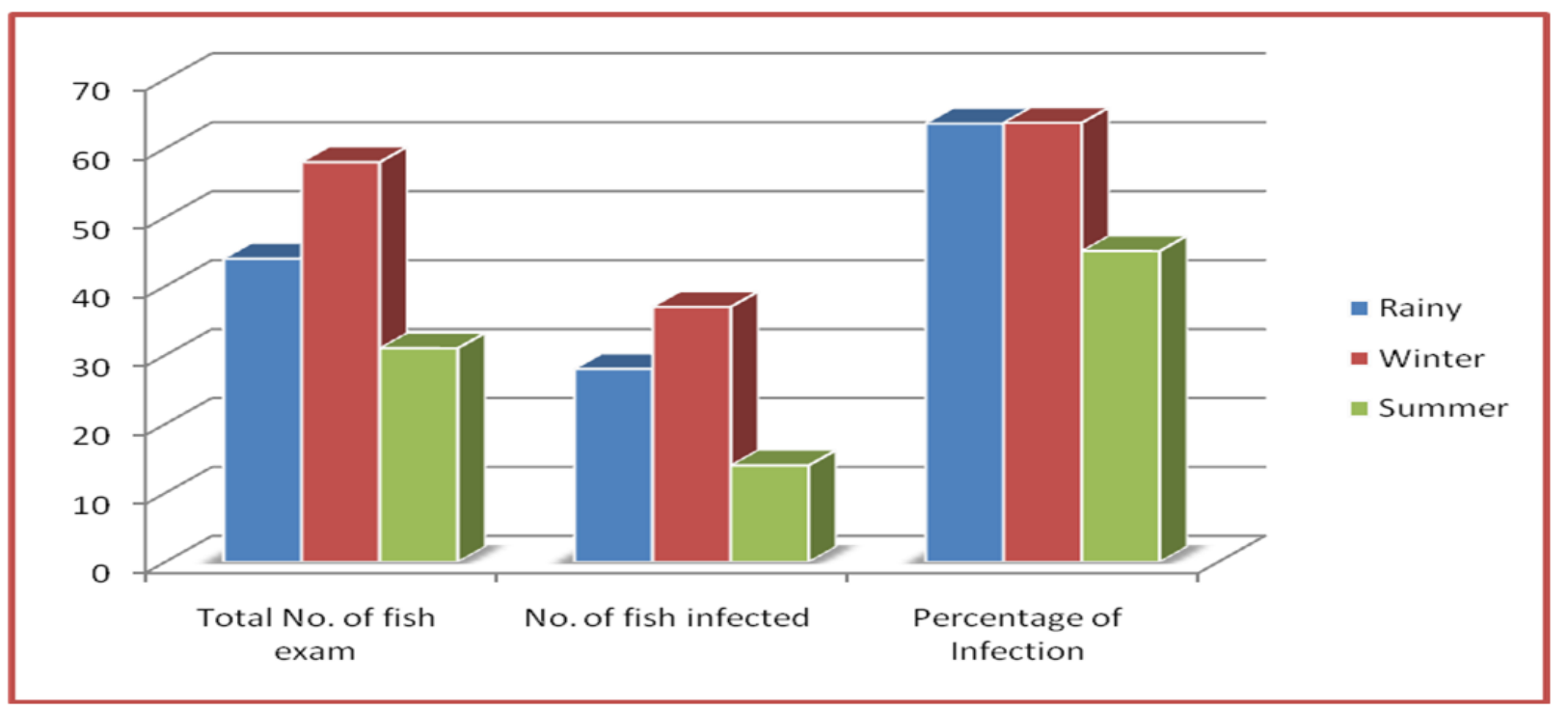

Fig 4: Seasonal variation in overall prevalence of trematode infection during 2017-18

The percentage of in the rainy season goes to $63.6 \%$, winter goes to $63.7 \%$ and summer was goes to $45.1 \%$. Monthly variations of infection of parasites were given (Fig 3.1).

\section{Discussion}

In the present examination the prevalence of infection was highest recorded in the both months of July and September, 2017. In the rainy seasons infection was higher percentage than winter. The lowest percentage was found in summer season. Feeding activates of the host may also be one of the reason (Auda Fares (2013) ${ }^{[1]}$. Furtherly found infection rate percentage was high during the periods of low temperature and low percentage infection during the high temperature (Kumari Gautam et al., 2018) ${ }^{[2]}$. The factors responsible for influencing the seasonal cycle of parasitic infection were namely temperature, host feeding habits, availability of infective intermediate hosts, and parasite maturation (Joanne Cable et al., 2017) ${ }^{[3]}$. Such parameters can easily be studied in a terrestrial or freshwater host (Binh cao and Pascale S. Guiton (2018) ${ }^{[4]}$ and Krishna and Sreeramulu, (1996) studied the prevalence and intensity of infection with Didymozoid parasite in Priacanthus hamrur, from waltair coast.

According to Rohde, (1993), temperature affects parasite faunas in two ways, 1) species numbers are greatly increased in warm seas and 2) species are different in cold and warm seas. Thus temperature is the most important factor responsible for differences in species numbers as well as variability in species.

The association of seasonal maturation with seasonal mortality occurs commonly amongst parasites of fish. Life cycle of these parasites may be short and not more than one

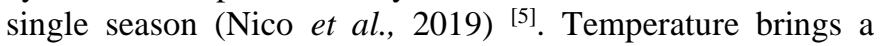
change in host behavior which indirectly effects the parasite recruitment and flow of parasites (Kennedy, 1975). The period of highest incidence of infection of parasites may be assumed as the lowest recruitment season as well as due to the elimination of parasites due to mortality. Rainy and winter seasons seem to be favourable for the parasite for infection. According to Bell and Burt, (1991) and Ellis et al., (2020) ${ }^{[6]}$; Vincenzo et al., (2020) ${ }^{[7]}$ parasite community diversity is positively correlated with hosts local prevalence. Manter, (1966) stated that if hosts are sparse, they may lack parasites, although other conditions may be favourable. He stated that a certain concentration of hosts and parasites is needed to assure the completion of life cycles.

Conclusion and Future Scope: Snakehead has vital functions with medicinal and pharmaceutical fresh water fish. In generally it is been used to treat wounds, alleviate pain, boosts energy and endowed with remarkable antiinflammatory, anti-nociceptive, platelet aggregation, as well as mild antimicrobial and antifungal properties. And also used as a therapeutics and nutritional supplements. Treating neurological diseases and in inducing regenerative potential of organs and cells. With reference of these applications we creating awareness to the remote area people and rural people who regularly consume murrels, due to indigenous helminthes pathogenicity may harm and causes different parasiting infections leads to the human abnormalities. Apart from have many advantages and many applications under research.

\section{Acknowledgement}

I Cordially thank the management for giving this opportunity to write a research article in a successive way to submit in a Journal in print form. Grateful to the UGC for providing financial support.

\section{References}

1. Auda Fares. Factors Influencing the Seasonal Patterns of Infectious Diseases Int J Prev Med 2013;4(2):128-132.

2. Kumari Gautam N, Kumar Misra P, Murari Saxena A. Seasonal Variation in Helminth Parasites of Snakeheads Channa Punctatus and Channa Striatus (Perciformes: Channidae) in Uttar Pradesh, India, Helminthologia, 2018;55(3):230-239.

3. Joanne Cable, Iain Barber, Brian Boag, Amy R Ellison, Eric R Morgan, Kris Murray, Emily L Pascoe et al. Global change, parasite transmission and disease control: lessons from ecology, Philos Trans R Soc Lond B Biol Sci 2017;372(1719).

4. Binh Cao, Pascale S Guiton. Important Human Parasites of the Tropics, frontiers for young minds 2018,

5. Nico J. Smit, Niel L. Bruce, and Kerry A. Hadfield Life Cycle and Life History Strategies of Parasitic Crustacea, Parasitic Crustacea 2019;3:179-266.

6. Ellis Vincenzo, Huang Xi, Westerdahl, Helena, Jönsson Jane, Hasselquist Dennis et al. Explaining prevalence, diversity, and host specificity in a community of avian 
haemosporidian parasites. Oikos 2020, 129. 10.1111/oik.07280.

7. Vincenzo A, Ellis Xi Huang Helena, Westerdahl Jane Jönsson Dennis, Hasselquist Júlio M, Neto Jan-Åke Nilsson Johan, et al. Explaining prevalence, diversity and host specificity in a community of avian haemosporidian parasites, Oikos 2020.

8. Rubina Mondal, Anuradha Bhat. Temporal and environmental drivers of fish-community structure in tropical streams from two contrasting regions in India, Plos one 2020.

9. Vijay Anand PE. Intelligence The fish farming industry of India, Second-largest freshwater fish producer has potential for further development, Global aqua culture alliance 2019.

10. Morales-Serna FN, Rodríguez-Santiago MA, Gelabert R. et al. Parasites of fish Poecilia velifera and their potential as bioindicators of wetland restoration progress. Helgol Mar Res 2019;73(1) https://doi.org/10.1186/s10152-0190522-1.

11. Prangnell, David, Castro, Leandro, Ali, Abdulmehdi et al. Some Limiting Factors in Superintensive Production of Juvenile Pacific White Shrimp, Litopenaeus vannamei, in No-water-exchange, Biofloc-dominated Systems. Journal of the World Aquaculture Society 2016;47:10.1111/jwas.12275.

12. Bichi A, Yelwa Sadiq. Incidence of piscine parasites on the gills and gastrointestinal tract of Clarias gariepinus (teugels) at bagauda fish farm, Kkano. Bayero Journal of Pure and Applied Sciences 2010, 3. 10.4314/bajopas.v3i1.58732.

13. Nmor JC, Egwunyenga AO, AKE Jeg. Observations on the intestinal helminth parasites of cichlids in the upper reaches of River Orogodo, a freshwater body in Delta State, Southern Nigeria. Tropical Freshwater Biology. 2003, 12. 10.4314/tfb.v12i1.20883.

14. Marcogliese, David. Parasites: Small Players with Crucial Roles in the Ecological Theater. Eco Health. 2004;1:151-164. 10.1007/s10393-004-0028-3.

15. Garcia LS, Arrowood M, Kokoskin E, Paltridge GP, Pillai DR, Procop GW et al. Laboratory diagnosis of parasites from the gastrointestinal tract. Clin Microbiol Rev 2018;31:e00025-17. https:// doi.org/10.1128/CMR.00025-17.

16. Stothard J, Littlewood DTJ, Gasser R, Webster, Bonnie. Advancing the multi-disciplinarity of parasitology within the British Society for Parasitology: Studies of hostparasite evolution in an ever-changing world. Parasitology. 2018:145:1-6. 10.1017/S0031182018001476.

17. Gozlan, Rodolphe, Britton, Rob, Cowx, Ian et al. Current knowledge on non-native freshwater introductions. Journal of Fish Biology. 2010:76:751-786. 10.1111/j.1095-8649.2010.02566.x.

18. Kiruba-Sankar R, Raj J, Saravanan K, Kumar, Lohith, Angel et al. Invasive Species in Freshwater EcosystemsThreats to Ecosystem Services 2018. 10.1016/B978-0-12813064-3.00009-0. 